\title{
A VOLATILIDADE DOS RELACIONAMENTOS FAMILIARES E A PRÁTICA DA ALIENAÇÃO PARENTAL: UMA ANÁLISE ACERCA DA OMISSÃO LEGISLATIVA DE TUTELA PREVENTIVA-INIBITÓRIA
}

\author{
THE VOLATILITY OF FAMILY \\ RELATIONSHIPS AND THE PRACTICE OF \\ PARENTAL ALIENATION: AN ANALYSIS \\ OF THE LEGISLATIVE OMISSION OF \\ PREVENTIVE-INJUNCTIVE PROTECTION
}

\section{Mariana Serafim Zanette ${ }^{1}$ \\ Sheila Martignago Saleh ${ }^{2}$}

\begin{abstract}
Resumo: O objetivo geral do presente artigo é promover uma reflexão sobre a volatilidade dos relacionamentos familiares e a prática da alienação parental. Como objetivos específicos, busca-se estudar a formação da multiparentalidade, a volatilidade dos relacionamentos familiares, a alienação parental e analisar a omissão legislativa de tutela preventiva-inibitória à violência psicológica familiar contra as crianças e os adolescentes, dada a importância
\end{abstract}

do tema devida à forte reprovabilidade social da conduta e por ser uma questão sócio-familiar que vem preocupando e ganhando repercussão cada vez maior no âmbito jurídico. No tocante ao método empregado para a confecção do artigo, utilizou-se o indutivo, observando-se o processo histórico-vivencial das famílias brasileiras conforme aquilo que normalmente acontece na sociedade, com supedâneo em pesquisa bibliográfica, jurisprudencial e na

1 Bacharela em Direito pela Universidade do Extremo Sul Catarinense (Unesc), pósgraduanda em Direito Público pela Escola Superior da Magistratura do Estado de Santa Catarina (Esmesc) e Residente Judicial na $1^{\mathrm{a}}$ Vara Cível da Comarca de Criciúma/SC. E-mail: mari_szanette@hotmail.com.

2 Bacharela em Ciências Jurídicas pela Universidade de Braz Cubas, mestre em Ciências Jurídicas pela Universidade do Vale do Itajaí (Univali), assessora acadêmica da Diretoria de Extensão, Cultura e Ações Comunitárias da Universidade do Extremo Sul Catarinense (Unesc). E-mail: sheilamsaleh@hotmail.com. 
legislação brasileira em vigor. Conclui-se que a exposição das crianças e dos adolescentes à sucessivas e novas formações e rompimentos de filiação socioafetiva (volatilidade dos relacionamentos familiares) é extremamente prejudicial ao desenvolvimento psíquico que mostra-se salutar uma providência urgente pelo Poder Legislativo de instituir tutela preventiva-inibitória às práticas de violência psicológica familiar, principalmente quanto à prática de alienação parental.

Palavras-chave: Multiparentalidade. Estado de filiação. Alienação parental. Omissão legislativa de tutela preventiva-inibitória.

Abstract: The general objective of this article is to promote a reflection on the volatility of family relationships and the practice of parental alienation. As specific objectives, we intend to study the formation of multiparentality, the volatility of family relationships, parental alienation and analyze the legislative omission of preventive-inhibitory protection against family psychological violence involving children and adolescents, given the importance of the theme due to the strong social reproach of conduct and because it is a socio-familial issue that has been worrying and gaining increasing repercussion in the legal scope. The method used to do the article was the inductive, observing the historical-experiential process of Brazilian families according to what normally happens in society, using bibliographic research, jurisprudence and Brazilian legislation in force. It is concluded that the exposure of children and adolescents to successive and new formations and disruptions of socio-affective affiliation (volatility of family relationships) is extremely detrimental to psychic development and this asks urgent step by the Legislative Power to institute preventive-inhibitory guardianship to practices of family psychological violence, mainly regarding the practice of parental alienation.

Keywords: Volatility of Family Relationships. Multiparentality. State of Membership. Parental Alienation. Legislative Omission of Preventive-inhibitory. Guardianship.

\section{INTRODUÇÃO}

O presente artigo tem como objetivo geral promover uma reflexão sobre a volatilidade dos relacionamentos familiares e a prática da alienação parental. No escopo de atingir o objetivo, o leitor percorrerá, inicialmente, uma leitura a respeito das mutações ocorridas na estrutura organizacional das famílias brasileiras a partir do fenômeno da Constitucionalização do Direito Civil, sobretudo, sob uma análise crítica acerca do comportamento legislativo com relação às mudanças, a fim de que possa compreender como se deu o reconhecimento socio- 
jurídico da filiação socioafetiva, a inserção do instituto da multiparentalidade no ordenamento jurídico pátrio e, consequentemente, seus reflexos nas relações intrafamiliares e na vida das crianças e dos adolescentes.

Após, será feita uma abordagem referente à volatilidade dos relacionamentos familiares e o estado de filiação, inserido num contexto sociofamiliar de sucessivas formações e rompimentos de relações socioafetivas (multiparentais), por meio da qual se verificará os prospectivos impactos psicológicos causados nas crianças e nos adolescentes e, por fim, defronte a esse cenário, será discorrido sobre a importância e a necessidade de uma atuação preventiva-inibitória do Estado-legislador.

Por último, trará em seu bojo uma das práticas mais degradantes de violência psicológica familiar contra as crianças e os adolescentes: a alienação parental. Porém, essa temática será debatida sob um ponto de vista diferente, na qual se examinará a Lei da Alienação Parental (Lei n. 12.318/2010) e, posteriormente, a recente Lei n. 13.431/2017 e seu Decreto regulamentador n. 9.603/2018, no escopo de averiguar se há suporte legislativo, em termos práticos e eficazes, de tutela preventiva-inibitória que vise prevenir e até evitar a prática dessa conduta ilícita nos núcleos familiares, deveras gravosa às crianças e aos adolescentes.

\section{O INSTITUTO DA MULTIPARENTALIDADE}

Completando 30 anos de sua promulgação, a Constituição Federal da República de 1988 (BRASIL, 1988) atribuiu uma nova releitura às normas jurídicas brasileiras, sob o propósito primordial de concretizar os direitos fundamentais e sociais insculpidos na Carta Magna e, não por acaso, o emprego do fenômeno da constitucionalização no sistema jurídico brasileiro torna-se cada vez mais recorrente, conquistando espaço 
substancial nas doutrinas, nas jurisprudências dos Tribunais brasileiros e na prática forense, a partir de uma interpretação mais teleológica e proativa da Constituição.

Não diferente, a constitucionalização das normas integrantes do Direito Civil foi tão incisiva, que culminou numa nova organização do Codex, promulgada no ano de 2002 (BRASIL, 2002). Em suma, a visão patrimonialista e individualizada cedeu lugar à socialidade e à coletividade. Primou-se pela integração dos princípios constitucionais nos institutos do direito privado para a efetivação dos direitos fundamentais, em detrimento do formalismo exacerbado e do excessivo rigor na aplicação das normas de direito civil.

De acordo com Feliciani (2016, p. 99):

Pode-se dizer, assim, que a aplicabilidade dos direitos fundamentais relativamente ao Estado (eficácia vertical) e/ou ao particular (eficácia horizontal) está contido no prelafado fenômeno, que é a constitucionalização do Direito Civil, que tem como eixo a proteção da dignidade da pessoa humana, que se realiza por meio da solidariedade social, resguardando a individualidade de cada um. E é essencialmente em razão da necessidade de especificação do direito na proteção dos diferentes e vulneráveis, evidenciando a pluralidade social, característica da pós-modernidade, que o Código Civil se descodifica.

Para Amin (2018, p. 86), entretanto, não obstante o avanço expressivo do Código Civil de 2002, não se pode olvidar que se trata de uma norma deficiente e um pouco ultrapassada:

Apesar da atualidade cronológica do Código Civil de 2002, a nova lei se mostra distante do significado atual do nosso sistema jurídico. A garantia do patrimônio era o fim almejado no antigo Código, considerado durante vasto tempo como a constituição do direito privado. Essa designação foi se mostrando desgastada diante da crescente legislação especial que melhor atendia às necessidades da sociedade moderna. A chamada "crise do direito civil" levou o direito 
comum a buscar sua unidade na Constituição da República, fundamento de validade de todo o ordenamento jurídico. Essemovimento foi batizado de constitucionalização do direito civil, cujo principal reflexo foi a mudança de paradigma substituindo-se o tradicional individualismo patrimonialista pela função social do sistema, fundada na dignidade da pessoa humana.

Oportuna reflexão de Amin, pois apesar da inserção desse novo paradigma constitucionalizado e humanizado no códice civilista vigente, a verdade é que a sociedade atual (pós-moderna) está passando por uma profunda e complexa mudança organizacional, que as recentes normas civis já se mostram frágeis à tutelar novas pretensões surgidas com essa realidade contemporânea (BOSCARO, 2002, p. 46).

Tal situação fica ainda mais evidente quando analisado o instituto civil do Direito de Família, mormente no que se refere ao tenro modelo institucional da família e o campo das relações familiares, pautados precipuamente na pluralidade, funcionalidade, solidariedade e afetividade, conforme leciona Hapner (2008a, p. 133):

Encontrar-se inserido em um modelo de família juridicamente reconhecido possibilita aos seus membros determinados direitos os quais não são reconhecidos isonomicamente para aqueles outros que, ao revés, estão sem a tutela estatal. Assim, a abertura do sistema para a pluralidade das entidades familiares significaria que as mais variadas formas de vivência familiar levem as vantagens de tutelas exclusivas a quem é considerado família.

Entretanto, para além das incontestáveis vantagens decorrentes do reconhecimento da pluralidade familiar, Hapner também adverte sobre o compromisso estatal com a prestação jurisdicional efetiva para dirimir os atuais conflitos jurídicos das diferentes relações familiares, provenientes dessa fase de transição:

Trata-se de uma relevante e complexa relação social, a qual 
deve o direito apreender para as consequências jurídicas das mais variadas ordens. Contudo, especialmente quando a adversidade se instaura é que se denota a necessidade de tutela pública em prol do princípio da prevalência da família, protegendo e, em alguns casos, substituindo o dever ético entre os seus membros. Tais proteções jurídicas muitas vezes encontram-se excluídas ou mesmo dificultadas aos filhos e pais socioafetivos, às famílias simultâneas, solidárias e recompostas bem como às uniões entre pessoas do mesmo sexo. Por tal motivo, o Direito de Família contemporâneo pugna por uma concepção de família não excludente, a qual reconheça a alteridade da "vida como ela é". (HAPNER, 2008b, p. 134).

Em razão desta vertente sociológica da família, cuja fonte passou a residir muito mais nos fatos e não em um modelo positivado juridicamente (NAMUR, 2008, p. 576), é que sobreveio discussão em torno da necessidade de albergar no ordenamento jurídico brasileiro as relações socioafetivas, merecedoras do amparo estatal, inclusive, a filiação socioafetiva (estado de filho afetivo):

Tal como aconteceu com a entidade familiar, a filiação começou a ser identificada pela presença do vínculo afetivo paterno-filial. Ampliou-se o conceito de paternidade, que compreende o parentesco psicológico, que prevalece sobre a verdade biológica e a realidade legal. A paternidade deriva do estado de filiação, independentemente de sua origem, se biológica ou afetiva. A ideia da paternidade está fundada muito mais no amor do que submetida a determinismos biológicos. (DIAS, 2015a, p. 389).

Sob essa nova óptica, a definição jurídica de filiação, chamada por Villela (1979, p. 415) de "desbiologização da paternidade", segundo a qual a verdade real - mãe/pai é o que cria e dá amor, "numa espécie de adoção de fato" (DIAS, 2015b, p. 406) - passou a prevalecer sobre o direito natural dos genitores biológicos, não demorou muito para que diversas demandas de retificação de registro civil fossem ajuizadas pelos filhos, devi- 
damente representados (geralmente pelas mães), fundadas na desconstituição da paternidade biológica, substituindo-a pela socioafetiva, com o devido amparo legal da Lei n. 11.924/2009 (BRASIL, 2009), que para Madaleno (2013, p. 13):

representa um bom avanço no âmbito da filiação socioafetiva, especialmente quando a adoção do sobrenome do padrasto ou da madrasta advém de uma situação fática de completo abandono material e psicológico do genitor biológico, e o enteado se encontra totalmente integrado na nova comunidade familiar.

Afora o contexto acima citado, a filiação socioafetiva também despertou a propositura de novas demandas judiciais baseadas na inclusão da paternidade afetiva no registro civil, mas com a manutenção da paternidade biológica. Emerge daí, portanto, a coexistência das paternidades biológica e afetiva, vedando a discriminação e a hierarquização entre elas, configurando o que a doutrina e a jurisprudência pátria convieram chamar de Multiparentalidade ou de Pluriparentalidade, referidas igualmente como Famílias Reconstruídas, Reconstituídas, Recompostas, Binucleares ou Mosaicos:

Nessa perspectiva, convém transcrever a conceituação dada por Pereira (2012, p. 205):

Também se inclui nesta categoria de família (pluriparental) aquelas chamadas reconstruídas, reconstituídas, binucleares e famílias "mosaicos", usualmente formada pelo par e os filhos advindos de relações conjugais anteriores, surgindo assim as figuras do padrasto e da madrasta, historicamente associadas a uma figura maligna, que busca substituir a mãe e/ou o pai. Havendo descendentes de famílias anteriores de ambos os lados, estes passarão a desenvolver uma convivência familiar sem elo de consanguinidade, mas serão, sim, filhos do coração.

Do ponto de vista positivo, a formação da multiparentalidade registral, além de espelhar a realidade vivencial de muitas 
crianças e adolescentes, oriunda do divórcio ou da dissolução do vínculo afetivo entre os genitores e a subsequente construção de um novo núcleo familiar (genitora e novo pai e/ou genitor e nova mãe), propõe uma reconfiguração estrutural de família. Nela a convivência entre os componentes é harmoniosa e proporciona à prole um convívio sadio com as duas figuras paternas, que atende aos anseios e ao livre desenvolvimento da personalidade, em especial, em um momento particularmente difícil.

Em contrapartida, conquanto a multiparentalidade atenda aos direitos fundamentais dos infantes num espaço em que haja verdadeira rede de solidariedade, à primeira vista, tanto doutrina como jurisprudência, com o pensamento voltado em garantir às crianças e aos adolescentes o direito registral à multiparentalidade, se descurou antever que muito raramente lhes são assegurados a manutenção de vínculo e convivência com o genitor/a que não mais coabita sob o mesmo teto e que nem sempre há estabilidade afetiva entre o casal da família reconstituída (multiparental). O que resulta na exposição da prole a sucessivas e novas formações e rompimentos de filiação socioafetiva.

A partir daí é que emerge a problemática envolvendo a volatilidade das relações amorosas e a submissão da prole a sucessivas e novas formações e rompimentos de filiação socioafetiva (multiparentais). Uma realidade fática a ser vindicada pelos sujeitos que a compõe e enfrentada pelo Poder Judiciário, de modo que, sozinho, não bastará para tutelar as consequências jurídicas e fáticas decorrentes do esfacelamento dessa complexa composiçãofamiliar, necessitando da atuação legislativa, que há muito vem sendo advertida sobre sua omissão frente aos diversos efeitos da multiparentalidade.

Analisando o tema, Azambuja (2018, p. 11) enfatiza sobre a carência legislativa a respeito das implicações jurídicas do reconhecimento da multiparentalidade para as crianças e adolescentes: 
Um dos temas atuais do direito de família mais controversos certamente é o que diz respeito à multiparentalidade. Isso porque, por mais nobre que nos pareça a ideia de dar a uma pessoa mais de um pai ou mais de uma mãe, juridicamente não nos parece que a jurisprudência, sozinha, conseguirá dar conta da demanda que se inicia. Em termos conceituais, podemos definir tal instituto como sendo o registro civil de pessoa natural em nome de mais de duas pessoas, gerando, assim, uma filiação com múltiplos pais. No dia 27 de fevereiro de 2018, foi realizada consulta no site do Tribunal de Justiça do Rio Grande do Sul, colocando no filtro a palavra "multiparentalidade", e tão somente 12 (doze) resultados foram dados como resultado da pesquisa. (AZAMBUJA, 2018, p. 11).

Frise-se que, o Instituto Brasileiro de Direito de Família (IBDFAM) editou, em 22-11-2013, o Enunciado $9^{\circ}$, confirmando que a multiparentalidade gera efeitos jurídicos (IBDFAM, 2013).

Todavia, ainda que os efeitos da multiparentalidade (sejam eles positivos ou negativos) sejam supridos pela atuação jurisdicional (protagonismo e ativismo judicial) em concomitância com o vasto acervo doutrinário, é notório que este assunto ainda clama por uma segurança jurídico-normativa e uma análise mais acurada das suas consequências, especialmente num contexto que envolve crianças e adolescentes a sucessivas e novas formações e rompimentos de filiação socioafetiva (multiparentais).

Tanto é prova disso, que dentre as escassas normas civilistas que tratam sobre a matéria, como por exemplo a do art. 1.611 do Código Civil (BRASIL, 2002) discute-se atualmente a sua constitucionalidade diante do princípio do melhor interesse da criança e do adolescente, visto que referido diploma legal exige o consentimento do cônjuge para a permanência do filho do outro cônjuge no lar conjugal. (GAMA, 2008, p. 193).

Dito isso, defende Amaro (2013, p. 129): 
Identificada a pluriparentalidade, ou seja, a filiação com mais de duas pessoas, mister identificar os encargos decorrentes. A coexistência das duas formas de paternidade, a biológica e a socioafetiva, gera demandas sobre os direitos reflexos dessas relações, como é o caso do direito ao conhecimento da origem genética, da obrigação alimentar e do direito sucessório, em que verifica-se que, mais uma vez, o judiciário exerce um papel de destaque na solução dos conflitos, em razão da omissão legislativa sobre o assunto.

É clarividente, portanto, que não obstante a irrefutável consagração da filiação socioafetiva e da entidade familiar formada pela multiparentalidade, merecedora de efetiva tutela jurisdicional estatal por força da supremacia irrefragável da Carta Magna de 1988, não há, por outro lado, como fechar os olhos para a morosidade legislativa com relação aos impactos negativos provocados na integridade psíquica das crianças e dos adolescentes, quando expostos a sucessivas e novas formações e rompimentos de filiação socioafetiva (multiparentais).

\section{A VOLATILIDADE DOS RELACIONAMENTOS FAMILIARES E O ESTADO DE FILIAÇÃO}

Com a subsequente remodelação da estrutura social-familiar, consubstanciada por laços de afetividade, a partir da qual se atribuiu eficácia jurídica à filiação socioafetiva e às entidades familiares fundadas na multiparentalidade, emergiu desse contexto, contudo, discussões referentes à inconstância das relações familiares, com especial relevo para os prospectivos impactos causados nos infantes, protegidos pelo Estatuto da Criança e do Adolescente (Lei n. 8.609/90 - ECA). (BRASIL, 1990).

A esse respeito é esclarecedora a lição de Petrini (2004, p. 43-44):

Na sociedade contemporânea, a família é considerada um valor, ideal que a maioria da população cultiva. No entanto, nestas últimas décadas, a família passa por grandes mudan- 
ças, que a tornam particularmente vulnerável. Estão mudando o modo de entender e o modo de viver o amor e a sexualidade, a fecundidade, o relacionamento entre homem e mulher. A família encontra-se em constante mudança por participar dos dinamismos próprios das relações sociais. O processo social dos últimos séculos acelerou as mudanças, com consequências substanciais em todos os aspectos da convivência humana. (PETRINI, 2004, p. 43-44, grifo nosso).

É a partir desses “dinamismos”, que retratam a família brasileira, que alguns doutrinadores, como Petrini, vêm alertando sobre a vulnerabilidade dos vínculos de afetividade entre os integrantes de diversos núcleos familiares e o quão essa situação acaba influindo negativamente na vida de cada indivíduo que a compõe, intensificado ainda mais nas crianças e nos adolescentes.

A exemplo, pode-se citar a opinião crítica de Calderón com relação a sucessivas formações e rompimentos de novas uniões afetivas, justamente porque apresentam ser um campo fértil para inconstante reorganização estrutural da família, cada qual com sua especificidade, merecendo um tratamento jurídico adequado ao respectivo tipo:

Nesse aspecto, em face das relações afetivas contemporâneas envolverem imbricadas situações pessoais - cada vez mais complexas (relacionamentos mais curtos, novos casamentos e divórcios, diversas uniões subsequentes, novos convívios com companheiros do seu genitor, multiparentalidade, entre outros) - não se aconselha uma solução única para casos que podem ser distintos, o que pode trazer dificuldades fáticas. As relações familiares são influenciadas por incontáveis pormenores e fatos que se sucedem ao longo do tempo, na intimidade do lar, no torvelinho das relações em família. (CALDERÓN, 2013, p. 384).

É possível inferir, desse modo, que ao mesmo tempo que se prestigia os arranjos familiares socioafetivos tão espontâneos 
e a constituição de entidades multiparentais, comprometidos em garantir um convívio familiar provido de afeto e de mútua assistência, também é possível presenciar na vida cotidiana e corriqueira das famílias um comportamento volátil, característica inerente ao próprio ser humano, detentor de particularidades e anseios imediatos (PETRINI, 2004b, p. 60).

No exercício dessa análise, atenta às peculiaridades do quadro fático referido acima, a Ministra Nancy Andrighi, em sede de Recurso Especial n. 1.383.408/RS26, julgado em 1505-2014, alertou que é preciso evitar que o "estado de filiação fique à mercê da volatilidade dos relacionamentos amorosos" (BRASIL, 2014), reportando-se ao caso concreto:

Em situações como a dos autos, há que se ter em mente que a fragilidade e a fluidez dos relacionamentos entre os seres humanos não deve perpassar as relações entre pais e filhos, as quais precisam ser perpetuadas e solidificada. Em contraponto à instabilidade dos vínculos advindos dos relacionamentos amorosos ou puramente sexuais, os laços de filiação devem estar fortemente assegurados, em atenção ao interesse maior da criança.

Reforça esse pensamento Veloso (2016, p. 469):

A questão é que esse gesto do companheiro (ou até mesmo do namorado) da mãe é motivado pela paixão, pela relação amorosa que está vivenciando. Eventualmente, quando os sentimentos se esvaem, acaba o envolvimento e a paixão se transforma em rancor, até para escapar das obrigações (alimentos, etc.), o pai pretende desfazer ou desconstituir o registro outrora realizado, descartar o filho.

Porém, convém deixar claro que o rompimento da filiação socioafetiva pelo insucesso do relacionamento com a genitora, manifestamente não atende ao superior interesse da criança/ adolescente, vez que como Dias (2015c, p. 407) explica:

Como foi o envolvimento afetivo que gerou a posse do estado de filho, o rompimento da convivência não apaga o 
vínculo de filiação que não pode ser desconstituído. Assim, se depois do registro, separam-se os pais, nem por isso desaparece o vínculo de parentalidade. Persistindo a certeza de quem é o pai, ou seja, mantida a posse de estado de filiação, não há como desconstituir o registro.

Não pairam dúvidas, portanto, que a construção da entidade familiar multiparental é fruto do crescimento exponencial de divórcios e de dissolução da sociedade conjugal, seguidos pela concepção de um novo núcleo familiar e, com isso, o surgimento da filiação socioafetiva (multiparental), a qual, porventura, poderá vir seguida de novos estados de filiação em decorrência da ruptura do relacionamento amoroso entre a genitora e o pai socioafetivo primitivo - defluência natural da volatilidade das relações humanas. No entanto, essa realidade pode trazer a violação dos direitos fundamentais da criança e do adolescente pela ausência de uma estrutura familiar sólida, que reflete no seu desenvolvimento social e psíquico, mormente quando há um convívio desarmonioso e conflitante entre a genitora e as figuras paternas, gerando o distanciamento forçado da prole com àquele que mantém elo de afetividade.

Tal complexidade sociojurídica justifica a proeminência deste tema, reflexão que conduz à quebra da idealização em torno da multiparentalidade, levando-se em conta que em eventual processo de sucessivas e novas formações/rompimentos da filiação socioafetiva, podeacarretar fortes consequências às crianças e aos adolescentes ao ser confrontada com um ambiente familiar conflituoso.

De forma clara e objetiva, apresenta Bordallo (2018a, p. 198) algumas das consequências:

As várias faces da maternidade e da paternidade - jurídica, biológica e socioafetiva - podem não coincidir entre elas e trazer complexidades queafetam a formação do filho. Inúmeros embates jurisprudenciais de alta relevância têm pontificado a realidade das famílias que, recompostas 
ou plurais, posicionaram os filhos em lugares diferentes, gerando, por vezes, instabilidade identitária. (BORDALLO, 2018a, p. 198, grifo nosso).

Sob esse prisma, acrescenta Grisard Filho (2010, p. 69/70):

O modelo de família atual, fundado na livre eleição do casal, no amor e no afeto, denota uma fragilização dos vínculos conjugais, pois, quando se instala o desamor, diminui a comunicação e desaparece o afeto, fracassam os projetos biográficos comuns e desmoronam as ilusões, mais facilmente chega o divórcio através de fórmulas cada vez mais e mais facilitadoras introduzidas pelo Estado-legislador. Esse mesmo Estado, por outro lado, fortalece a solidariedade intrafamiliar mediante a afirmação constitucional da corresponsabilidade parental, da proteção integral ao menor.

Da abordagem de Grisard Filho, interessante destacar o papel do Estado-legislador no cenário de dissolução do vínculo conjugal e do rompimento das relações socioafetivas/ multiparentais, o qual exerce dupla função evidentemente distinta, posto que, de um lado, desburocratizou o processo de dissolução/divórcio dos casamentos, das sociedades conjugais e, agora, das relações socioafetivas, atribui-lhes característica de direito potestativo (que só depende da vontade de uma das partes para obter a procedência da demanda declaratória), e, por outro lado, como consequência do esfacelamento destas uniões, a necessária interferência na estrutura familiar a fim de tutelar os direitos das crianças e dos adolescentes nestes casos, protegendo-os de eventual abuso do poder familiar.

Discorre Bordallo (2018b, p. 207):

Pela perspectiva psicológica, o rompimento da relação afetiva dos pais não pode representar para o filho uma violação à sua integridade biopsíquica, cabendo ao Estado criar instrumentos jurídicos e sociais, para que a convivência com os pais se perpetue, principalmente nos momentos de crise de família.

Nas sábias palavras de Maciel (2009a, p. 182-183): 
A justiça de família atual, portanto, é chamada a trazer a paz social nos momentos de ruptura familiar, mas não com a finalidade de salvar o que já se deteriorou e nem de buscar um culpado pelo desamor. A justiça de família, pelo contrário, deve ter por meta promover a proteção de todo o núcleo familiar, posto que das decisões particulares do casal se extraem reflexos para os filhos menores que passarão a conviver em um novo núcleo familiar, monoparental ou em uma família recomposta, que poderá suprir adequadamente, se devidamente orientada, os direitos dos infantes.

Porém, elucida a doutrinadora acima citada que, a partir de sua primorosa análise técnica conjunta com profissionais psicólogos, respeitante aos estágios do ciclo de desfazimento de uma família, especificamente quanto ao quarto estágio, aferiu-se que:

A perda de um dos pais na casa, as muitas mudanças no funcionamento da família, e os estresses em cada progenitor, que afetam sua capacidade de serem pais, tudo isso contribui para o impacto sobre os filhos. Quanto mais o progenitor não residente for excluído, maior será o potencial de disfunção familiar. Advertem as mencionadas pesquisadoras que os papéis, as fronteiras e a estrutura hierárquica da família não só se modificam, como também mudam os relacionamentos com todos os sistemas fora da família nuclear: a família ampliada, os amigos, o trabalho, a escola, a comunidade. Enfatizam que estas manifestações acontecem pela ausência de normas ou apoios sociais para as famílias divorciadas. (MACIEL, 2009b, p. 181).

À vista disso, depreende-se que é inequívoco o impacto psíquico nas crianças e nos adolescentes, fruto das consequências da ruptura do vínculo familiar, bem como a consequente constituição de sucessivas e novas famílias (multiparentais seja do lado paterno e/ou materno), as quais multiplicam-se, a cada dia, sem que lhes sejam conferidos a prestação de um serviço público preventivo organizado de assistência psicossocial e jurídica, com o propósito de coibir a exposição das crianças e adolescentes à violência intrafamiliar. 
Veronese e Sanches (2017, p. 145) ratificam o entendimento acima esposado, com respaldo constitucional insculpido no seu art. 226:

Em decorrência, nas situações de risco e no enfraquecimento dos vínculos familiares, as estratégias de atendimento deverão esgotar as possibilidades de sua preservação, que vão desde o auxílio alimentar, geração de emprego e renda, apoio socioeconômico até a elaboração de novas formas de convívio relacional e referências afetivas no grupo, como já estabeleceu o art. 226 da CF, dispondo que: "O Estado assegurará assistência à família na pessoa de cada um dos que a integram, criando mecanismos para coibir a violência no âmbito de suas relações.

Nessa toada, a recorrente fragmentação estrutural das instituições familiares e, subsequentemente, a inserção das crianças e dos adolescentes a novos núcleos familiares com diversos genitores, socioafetivos e biológico, é a mola propulsora para desencadear a prática de diversas condutas de violência no ambiente familiar - acaso não recebam o devido amparo estatal - como, principalmente, às de ordem psicológica, visto que as brigas entre os integrantes (genitores e novas figuras parentais) se tornam frequentes, tal como a atmosfera de competição entre eles do exercício do poder familiar e, a partir disso, a tendência de a mágoa e o rancor do casal parental, germinados pela separação, serem introduzidos nos filhos, como meio de vingança.

Todos esses episódios são apenas "ponta do iceberg" de um sem-número de casos de violência e risco à integridade das crianças e adolescentes, enquadradas neste contexto de rompimento da convivência entre os pais, que chegam ao Judiciário já em estado crítico. Alguns comportamentos tornaram-se tão repetitivos, que o Estado-legislador, juntamente com o judiciário e doutrinadores decidiram tipificá-los, conforme se verá adiante. 


\section{A PRÁTICA DAALIENAÇÃO PARENTAL COMO FORMA DE VIOLÊNCIA PSICOLÓGICA FAMILIAR CONTRAAS CRIANÇAS E OS ADOLESCENTES E A OMISSÃO LEGISLATIVA DE TUTELA PREVENTIVA-INIBITÓRIA}

Em breve síntese, com tudo que foi constatado até então, a formação da entidade multiparental aliada à consequente inserção de novos laços familiares afetivos, é um cenário propenso à desestruturação do ambiente familiar e à prática de violências físicas e psicológicas contra os infantes e os adolescentes.

Prefere-se dar especial atenção à violência psicológica por ser uma agressão mais silenciosa, de difícil diagnóstico e que, na maioria das vezes, quando descoberta, já em estágio avançado, revela um quadro complexo e de difícil reversão.

Nessa ordem de ideias, faz-se necessário analisar os desdobramentos da mais assídua conduta de violência psicológica no âmbito familiar contra as crianças e os adolescentes, qual seja, a alienação parental.

Promulgada em 26 de agosto de 2010, a Lei n. 12.318/2010 que trata especificamente da alienação parental (SAP), listou um rol meramente exemplificativo de condutas - bastantes reiteradas no Judiciário - caracterizadoras da prática que compromete o desenvolvimento sociopsicológico das crianças e dos adolescentes, veja-se:

Art. $2^{\circ}[\ldots]$ Parágrafo único. São formas exemplificativas de alienação parental, além dos atos assim declarados pelo juiz ou constatados por perícia, praticados diretamente ou com auxílio de terceiros:

I- realizar campanha de desqualificação da conduta do genitor no exercício da paternidade ou maternidade;

II- dificultar o exercício da autoridade parental; 


\section{III- dificultar contato de criança ou adolescente com genitor;}

\section{IV- dificultar o exercício do direito regulamentado de convivência familiar;}

\section{V- omitir deliberadamente a genitor informações pes- soais relevantes sobre a criança ou adolescente, inclusi- ve escolares, médicas e alterações de endereço;}

VI- apresentar falsa denúncia contra genitor, contra familiares deste ou contra avós, para obstar ou dificultar a convivência deles com a criança ou adolescente;

VII- mudar o domicílio para local distante, sem justificativa, visando a dificultar a convivência da criança ou adolescente com o outro genitor, com familiares deste ou com avós. (BRASIL, 2010, grifo nosso).

Dentre as condutas acima listadas, dá-se ênfase àquelas que estão postas em negrito, uma vez que são comumente praticadas e que abarcam no seu contexto fático os demais atos de alienação parental. No caso do inciso I, verbi gratia, Duarte (2007, p. 204) preceitua:

As críticas e desvalorizações em relação ao ex-cônjuge, são profundamente perniciosas para os filhos, trazendo-lhes muitos conflitos, pois estes idealizam os pais, identificando-se com alguns de seus traços e com algumas de suas condutas. Por exemplo: Como as crianças reagirão frente à figura paterna, constantemente humilhada por sua mãe e outros familiares, recebendo qualificações depreciativas, carregadas de ódio e ressentimento? Ou, caso contrário, quando a mãe é também recriminada e desvalorizada, deixando a criança confusa diante dos ditos do pai e familiares, que entram em contradição com os sentimentos amorosos que ela vivencia junto à mãe?

Esse comportamento de desmoralização da imagem do outro genitor(a) e/ou do pai socioafetivo primitivo perante ao filho(a) é um caminho adotado pelo alienador que na maioria das vezes 
é o guardião - a genitora ou o pai - com a intenção de prejudicar a convivência com o outro genitor/pai socioafetivo ou mãe.

Nesse contexto também se desconstrói a presunção de que é o guardião somente - a genitora - que comete tal ato no intuito de privar o filho do convívio com o genitor/pai socioafetivo primitivo. Outros integrantes do grupo familiar, do mesmo modo, podem se enquadrar em um perfil de eventual alienador, interiorizando na criança ou adolescente sentimentos de raiva, medo e atitudes de desprezo em relação a um dos genitores ou pais socioafetivos.

A prática de alienação parental acontece, na maioria dos casos, em razão do rompimento do relacionamento amoroso, como forma de punição ao outro genitor, usando a dificuldade da convivência familiar com os filhos, como um castigo.

A multiparentalidade acaba por aumentar a possibilidade de ocorrência de alienação parental, e consequentes violências psicológicas, na vida dessas crianças e adolescentes, devido à volatilidade dos relacionamentos e rompimentos.

A despeito do inciso VI, do art. $2^{\circ}$, da Lei n. 12.318/2010 (BRASIL, 2010), por sua vez, que aponta o cometimento de falsas denúnciascontra genitores/pais socioafetivos e/ou demais componentes familiares para obstar a convivência com o infante, normalmente o tipo de acusação que se observa no cotidiano forense - seja durante o trâmite de ações em que se discute o divórcio, e posteriormente onde a criança/adolescente é inserida em sucessivos e novos núcleos familiares, constituídos por um de seus genitores ou por ambos diante de novos enlaces, surgindo, assim, a família reconstituída - é o abuso sexual:

No entanto, lamentavelmente há muitos relatos de falso alarme de abuso sexual de filho, denunciado por um dos genitores, objetivando o afastamento do pretenso agressor da convivência familiar, Esta prática é considerada uma forma nefasta de abuso psicológico, tão ou mais prejudi- 
cial à formação psíquica do filho quanto à própria violência física ou sexual. Na psicologia foi descrita como síndrome da alienação parental. (MACIEL, 2018, p. 226).

Moura (2015, p. 34) expõe, com precisão, como geralmente acontece no seio familiar os episódios de falsas memórias (expressão cunhada por ela e demais doutrinadores para se referir à falsa denúncia), introduzidas pelo alienador na criança/ adolescente, vítima da Síndrome da Alienação Parental (SAP):

Ponto característico da SAP e extremamente devastador é a "implantação de falsas memórias", que ocorre quando o detentor da guarda distorce relatos feitos pela criança sobre o que ocorreu quando estava com o outro. A criança chega em casa contando uma passagem inocente que teve com o outro genitor quando em visita; o detentor da guarda repete a estória para a criança alertando-a como se aquele fato tivesse sido negativo, até que a criança acredite que o outro é mesmo capaz e que realmente tivesse feito aquilo falado pelo alienante. A criança passa a se lembrar do fato então como contado pelo alienante, e não como realmente aconteceu. Com base nos fatos descritos pela criança após o processo de implantação de falsas memórias, surge mais uma nuance da alienação, que é a denúncia de abuso contra o genitor alienado A criança, influenciada pelo alienante, descreve situações que, distorcidas pelas falsas memórias, fundamentam acusações de abuso dos filhos pelo alienado.

Note-se, porém, que a men legis prevista no art. $6^{\circ}$ da Lei n. 12.318/2010 (BRASIL, 2010) apenas prevê a adoção pelos juízes de medidas de caráter punitivo e pedagógico para o alienador:

Art. $6^{\circ}$. Caracterizados atos típicos de alienação parental ou qualquer conduta que dificulte a convivência de criança ou adolescente com genitor, em ação autônoma ou incidental, o juiz poderá, cumulativamente ou não, sem prejuízo da decorrente responsabilidade civil ou criminal e da ampla utilização de instrumentos processuais aptos a inibir ou ate- 
nuar seus efeitos, segundo a gravidade do caso:

I- declarar a ocorrência de alienação parental e advertir o alienador;

II- ampliar o regime de convivência familiar em favor do genitor alienado; III- estipular multa ao alienador;

IV- determinar acompanhamento psicológico e/ou biopsicossocial;

V- determinar a alteração da guarda para guarda compartilhada ou sua inversão;

VI- determinar a fixação cautelar do domicílio da criança ou adolescente;

VII- declarar a suspensão da autoridade parental.

Em outras palavras, disciplina a atuação do Judiciário somente após apurado algum ato típico de alienação parental, o que evidentemente pode ser tardio para a reversão do quadro de Síndrome de Alienação Parental (SAP), cujos efeitos são delineados por Tosta (2013, p. 26):

Os efeitos nas crianças vítimas da Síndrome de Alienação Parental podem ser uma depressão crônica, incapacidade de adaptação em ambiente psicossocial normal, transtornos de identidade e de imagem, desespero, sentimento incontrolável de culpa, sentimento de isolamento, comportamento hostil, faltade organização, dupla personalidade e às vezes suicídio. Estudos têm mostrado que, quando adultas, as vítimas da Alienação tem inclinação ao álcool e às drogas e apresentam outros sintomas de profundo mal-estar. O sentimento incontrolável de culpa se deve ao fato de que a criança, quando adulta, constata que foi cúmplice inconsciente de uma grande injustiça ao genitor alienado. O filho alienado tende a reproduzir a mesma patologia psicológica que o genitor alienador.

Como se vê, a própria Lei da Alienação Parental não estatui medidas preventivas, apenas punitivas ao alienador e 
reparatórias à criança/adolescente já alienada. No entanto, aguardar o surgimento de algum elemento indicativo da prática de alienação parental para só então alcançar a proteção jurisdicional, não se desvela plenamente eficaz para atender aos anseios prementes diante da gravidade dos danos in re ipsa causados pela SAP.

Passados, então, sete anos da entrada em vigor da Lei n. 12.318/2010, em face da deficiência legislativa ora analisada, a recente Lei n. 13.431/2017 (BRASIL, 2017), a fim de suprir a omissão, "estabelece o sistema de garantias de direitos da criança e do adolescente vítima ou testemunha de violência", incluindo, no seu art. $4^{\circ}$, inciso II, alínea b, a alienação parental como forma de violência psicológica contra a criança e o adolescente e, como tal, merecedora da tutela preventiva-inibitória, assegurada pelo art. $1^{\circ}$ da Lex nova, in verbis:

Art. $1^{\circ}$. Esta Lei normatiza e organiza o sistema de garantia de direitos da criança e do adolescente vítima ou testemunha de violência, cria mecanismos para prevenir e coibir a violência, nos termos do art. 227 da ConstituiçãoFederal, da Convenção sobre os Direitos da Criança e seus protocolos adicionais, da Resolução no 20/2005 do Conselho Econômico e Social das Nações Unidas e de outros diplomas internacionais, e estabelece medidas de assistência e proteção à criança e ao adolescente em situação de violência. (BRASIL, 2017, grifo nosso).

Com efeito, há previsão no art. $14, \S 1^{\circ}$ da Lei n. 13.431/2017 (BRASIL, 2017) para a implementação, pelos diversos campos das políticas sociais públicas voltadas à proteção das crianças e adolescentes ("sistema de justiça, segurança pública, assistência social, educação e saúde"), de um conjunto de "ações articuladas, coordenadas e efetivas" a coibir a violência praticada contra as crianças e adolescentes.

Malgrada a referência, o Poder Executivo, incumbido de regulamentar os ditos mecanismos e ações integradas para dar- 
lhes fiel execução, expediu o Decreto n. 9.603/2018, promulgado em 10 de dezembro de 2018 (BRASIL, 2018).

Contudo, basta uma rápida leitura do citado Decreto regulamentador para perceber que, infelizmente, inexiste qualquer regulamentação específica a respeito dos mecanismos para prevenir e coibir a prática de violência contra as crianças e adolescentes (Quais são os mecanismos? A quem será atribuída tal função? De que forma serão executados?), além, também, da evidente omissão quanto ao "conjunto de ações" integradas (Que ações especificamente são essas? De que forma serão promovidas, organizadas e executadas?).

Há apenas "no papel" que "o sistema de garantia de direitos da criança e do adolescente vítima ou testemunha de violência”, previsto na Lei n. 13.431/2017 (BRASIL, 2017), intervirá nos casos de violência contra crianças e adolescentes, de forma a prevenir a prática destes atos (art. $3^{\circ}$, II, do Decreto $n$. 9.603/2018) (BRASIL, 2018).

Em termos práticos, exsurge que, a mera previsão genérica de adoção de mecanismos, ações integradas e intervenções prioritárias destinadas à prevenção e coibição de condutas violadoras à psique das crianças e adolescentes, em nada confere à Lei n. 13.431/2017 a mínima e necessária efetividade para alcançar seu objetivo teleológico, implicando às vítimas apenas uma falsa e vaga intuição protetiva.

À guisa de exemplo, cite-se o posicionamento do Juiz de Direito do Mato Grosso do Sul, Dr. Fernando Moreira Freitas da Silva, atual Vice-presidente da Comissão Nacional de Adoção do IBDFAM (Instituto Brasileiro de Família), que ao ser questionado acerca do Decreto ora exame, teceu as seguintes críticas:

É preciso notar que, infelizmente, ele não cumpriu adequadamente o seu papel de regulamentar a Lei 13.431/17, pois muito pouco trouxe de concreto àquilo que já estava pre- 
visto na própria lei federal. Ademais, transferiu para um ato conjunto dos Ministros de Estado da Justiça, da Segurança Pública, da Educação, do Desenvolvimento Social, da Saúde e dos Direitos Humanos a disposição de normas complementares para a implementação. Precisamos evitar essa técnica legislativa de sucessivas normas complementares, que acabam dando pouca ou nenhuma efetividade aos direitos das crianças e dos adolescentes [...] Percebe-se, portanto, a necessidade de uma integração total entre a rede de proteção, pois todas as entidades devem trabalhar de forma integrada para garantir um efetivo serviço de proteção aos infantes. (SILVA, 2018).

Para o Doutor e atual Desembargador do Tribunal de Justiça do Paraná, Mário Luiz Ramidoff, esta postura do Poder Legislativo e Executivo não é novidade:

Como medianamente se sabe, o legislador ordinário que busca nas exigências sociais a elaboração de regras que passem a regulamentar as atividades e comportamentos desenvolvidos nas diversas relações sociais, também, não pode deixar de estabelecer outras regras que importem na regulamentação dos procedimentos e metodologias de interpretação daquelas regras primeiras. Porém, o legislador ordinário, quando estabelece tais regras de interpretação, também, orienta-se pelo atendimento destas novas exigências sociais que, por suas complexidades, tornam-se, não raras vezes impossíveis de serem satisfeitas, motivo pelo qual o legislador constrói conceitos genéricos, como que, assim, outorgando indevidamente competências e atribuições para outras dimensões exponenciais - outras esferas e outro poderes constituídos - mediante tal artifício discursivo-legal. (RAMIDOFF, 2006, p. 141-142).

Nesse sentir, ante a inconteste inércia do Poder Legislativo e do Poder Executivo em regulamentar a Lei n. 13.431/2017 que, lançando apenas disposições ao léu, deixou de conferir o mínimo de concretude necessária para a implementação e operacionalização dos mencionados mecanismos e ações integradas a propiciar às crianças e aos adolescentes - notadamente na constância 
da ruptura da unidade familiar originária e após, na exposição sucessiva das crianças e dos adolescentes à novos núcleos familiares socioafetivos - a concessão de tutela preventiva- inibitória das práticas de violência psicológica familiar futura, como a alienação parental; mostra-se salutar uma providência urgente do Poder Público Executivo e Legislativo, pois, caso contrário, estar-se-ia diante de flagrante violação ao princípio da proteção integral aos direitos das crianças e dos adolescentes.

A Doutrina da Proteção Integral ${ }^{3}$ da criança e do adolescente adquiriu importância singular perante o ordenamento jurídico pátrio após a Convenção das Nações Unidas de Direitoda Criança datada em 20-11-1989 (BRASIL, 1990), muito embora nossa Constituição Federal, ainda que timidamente, já previa o primado da proteção integral à criança, de forma implícita no art. 227 (BRASIL, 1988), ao dispor que as crianças e os adolescentes são detentores de prioridade absoluta, devido ao estado peculiar de desenvolvimento da personalidade.

\section{CONCLUSÃO}

Por tudo que foi exposto, então, verificou-se que, a volatilidade dos relacionamentos é uma realidade fática das famílias brasileiras na contemporaneidade, donde provêm a crescente exposição das crianças e dos adolescentes à subsequente reconfiguração estrutural de convivência familiar, por sucessivas novas formações e rompimentos forçados de vínculos afetivos de filiação (multiparentais). Cenário muito propenso à prática de alienação parental, como forma de violência psicológica familiar contra as crianças e os adolescen-

3 Esta Doutrina afirma o valor intrínseco da criança como ser humano; a necessidade de especial respeito à sua condição de pessoa em desenvolvimento; o valor prospectivo da infância e da juventude, como portadora da continuidade do seu povo e da espécie e o reconhecimento da sua vulnerabilidade o que torna as crianças e adolescentes merecedores de proteção integral por parte da família, da sociedade e do Estado, o qual deverá atuar por meio de políticas específicas para promoção e defesa de seus direitos. (COSTA, 1992, p. 19). 
tes, pois, como se viu, é neste contexto que, não raras vezes, os genitores e os novos pais e/ou novas mães (socioafetivos) munidos por sentimento de vingança, ciúmes e competição, privam a prole do convívio sadio e harmonioso com os integrantes do grupo familiar, comprometendo a manutenção dos laços de filiação construídos e a própria integridade da criança e do adolescente, maiores vítimas desta conduta tão agressiva.

Frente a essa problemática, pôde ser averiguada a omissão legislativa de adoção de tutela preventiva-inibitória à prática de violência psicológica familiar, tal como a alienação parental, visto que ausente na própria Lei da Alienação Parental (Lei n. 12.318/2010) (BRASIL, 2010) e, mesmo após a recente Lei n. 13.431/2017 (BRASIL, 2017) e o Decreto "regulamentador" n. 9.603/2018 (BRASIL, 2018), segundo os quais apenas preveem a implementação de políticas sociais públicas e um conjunto de ações articuladas, coordenadas e efetivas a prevenir e coibir a violência (inclusive a psicológica) praticada contra as crianças e os adolescentes, em especial no seio familiar, nada dispondo a respeito, em termos práticos, a fim de conferir a mínima e necessária efetividade ao próprio comando legal.

Há muito tempo se clama urgência de uma atuação protetiva do Poder Legislativo no âmbito do Direito das Famílias, devido ao fato de que o Poder Judiciário vem adotando, mais do que nunca, uma postura ativista, porém, quando tão somente apurado algum ato típico da conduta violadora, mostrando-se tardio e frágil à salvaguardar, sozinho, as crianças e os adolescentes dos efeitos danosos da volatilidade dos relacionamentos familiares e da prática da alienação parental.

\section{REFERÊNCIAS}

AMARO, Cíntia Moura. As novas posturas jurídicas em prol da família a partir 
da codificação civil de 2002. Carlos Silveira Noronha (org.). Porto Alegre, Editora Sulina, 2013.

AMIN, Andréa Rodrigues. Dos direitos fundamentais. In: MACIEL, Kátia Regina Ferreira Lobo Andrade (coord.) Curso de direito da criança e do adolescente: aspectos teóricos e práticos. 11. ed. São Paulo: Editora Saraiva Educação, 2018.

AZAMBUJA, Mariana Menna Barreto. A evolução do direito de família: uma análise de temas atuais envolvendo as relações familiares. Revista Síntese Direito de Família. São Paulo, v. 19, n. 108, jun/jul. 2018.

BORDAllO, Galdino Augusto Coelho. Curso de direito da criança e do adolescente: aspectos teóricos e práticos. 11. ed. São Paulo: Editora Saraiva Educação, 2018.

BOSCARO, Marco Antônio. Direito de filiação. São Paulo: Editora Revista dos Tribunais. 2002.

BRASIL. Constituição da República Federativa do Brasil (1988). Disponível em: http://www.planalto.gov.br/ccivil_03/constituicao/constituicaocompilado.htm. Acesso em: 23 fev. 2019.

BRASIL. Decreto n. 9.603, de 10 de dezembro de 2018. Regulamenta a Lei n. 13.341/2017, de 4 de abril de 2017. Disponível em: http:/www.planalto.gov.br/ccivil_03/_Ato2015-2018/2018/Decreto/D9603.htm. Acesso em: 31 jan. 2019.

BRASIL. Decreto n. 99.710, de 21 de novembro de 1990. Promulga a Convenção sobre os Direitos da Criança. Disponível em: http://www.planalto.gov.br/ccivil_03/decreto/1990- 1994/D99710.htm. Acesso em: 23 fev. 2019.

BRASIL. Lei n. 8.069, de 13 de julho de 1990. Dispõe sobre o Estatuto da Criança e do Adolescente e dá outras providências. Disponível em: http://www.planalto.gov.br/ ccivil_03/LEIS/L8069.htm. Acesso em: 06 dez. 2018.

BRASIL. Lei n. 10.406, de 10 de janeiro de 2002. Dispõe sobre o Código Civil. Disponível em: http:/www.planalto.gov.br/ccivil_03/LEIS/2002/L10406.htm. Acesso em: 20 out. 2018 .

BRASIL. Lei n. 11.924, de 17 de abril de 2009. Altera o art. 57 da Lei no 6.015, de 31 de dezembro de 1973, para autorizar o enteado ou a enteada a adotar o nome da família do padrasto ou da madrasta. Disponível em: http://www.planalto.gov.br/ccivil_03/_Ato2007-2010/2009/Lei/L11924.htm. Acesso em: 18 mar. 2019.

BRASIL. Lei n. 12.318, de 26 de agosto de 2010. Dispõe sobre a Alienação Parental e altera o art. 236 da Lei no 8.069, de 13 de julho de 1990. Disponível em: http://www. planalto.gov.br/ccivil_03/_Ato2007-2010/2010/Lei/L12318.htm. Acesso em: 12 fev. 2019.

BRASIL. Lei n. 13.341, de 04 de abril de 2017. Estabelece o sistema de garantias de direitos da criança e do adolescente vítima ou testemunha de violência. Disponível em: http://www.planalto.gov.br/ccivil_03/_Ato2015-2018/2017/Lei/L13431.htm. Acesso em: 31 jan. 2019.

BRASIL. Superior Tribunal de Justiça. Recurso Especial n. 1.383.408/RS, Relatora: Ministra Nancy Andrighi. Data de julgamento:15 maio. 2014. Disponível em: http:// www.stj.jus.br/SCON/jurisprudencia/toc.jsp?processo $=1383408 \& b=A C O R \&$ thesaurus=JURIDICO\&p=tr. Acesso em: 15 dez. 2018. 
CALDERÓN, Ricardo Lucas. Princípio da afetividade no direito de família. Rio de Janeiro: Editora Renovar, 2013.

COSTA, Antônio Carlos Gomes. Natureza e Implantação do Novo Direito da Criança e do Adolescente. In: PEREIRA, Tânia da Silva (coord.). Estatuto da criança e do adolescente: lei n. 8.069/90: estudos sócio-jurídicos. Rio de Janeiro: Editora Renovar, 1992.

DIAS, Maria Berenice. Manual de direito das famílias. 10. ed. rev. atual. e ampl. São Paulo: Editora Revista dos Tribunais, 2015.

DUARTE, Lenita Pacheco Lemos. A guarda dos filhos na família em litígio: uma interlocução da psicanálise com o direito. Rio de Janeiro: Editora Lumen Juris Direito, 2007.

FELICIANI, Ana Lúcia Alves. A Descodificação do Direito de Família. In: NORONHA, Carlos Silveira (coord.). Temas de direito de família e de sucessões na atualidade: reexame dos estudos acerca dos efeitos secundários da sentença civil de mérito. Porto Alegre: Editora Sulina, 2016.

GAMA, Guilherme Calmon Nogueira. Princípios constitucionais de direito de família: guarda compartilhada à luz da lei n. 11.698/08: família, criança, adolescente e idoso. São Paulo: Editora Atlas, 2008.

GRISARD FILHO, Waldyr. Famílias reconstituídas: novas uniões depois da separação. 2. ed. São Paulo: Editora Revista dos Tribunais, 2010.

HAPNER, Adriana Antunes Maciel Aranha et al. O princípio da prevalência da família: a permanência do cuidar. In: PEREIRA, Tânia da Silva et al. (coord.). O cuidado como valor jurídico. Rio de Janeiro: Forense, 2008.

IBDFAM. Enunciando 09, de 22 de novembro de 2013. Disponível em: http:/www. ibdfam.org.br/conheca-o-ibdfam/enunciados-ibdfam. Acesso em: 15 nov. 2018.

MACIEL, Kátia Regina Ferreira Lobo Andrade. Cuidado e vulnerabilidade: aspectos jurídicos. In: OLIVEIRA, Guilherme; PEREIRA, Tânia da Silva (coord). São Paulo. Editora Atlas, 2009.

MACIEL, Kátia Regina Ferreira Lobo Andrade. Curso de direito da criança e do adolescente: aspectos teóricos e práticos. 11. ed. São Paulo: Saraiva, 2018.

MADALENO, Rolf. Curso de direito de família. 5. ed. rev. atual. e ampl. Rio de Janeiro: Editora Forense, 2013.

MOURA, Andréa Guedes Martins de. Um olhar sociológico sobre a disputa de guarda. Revista Síntese Direito de Família. São Paulo: Editora Síntese, v. 16, n. 91, p. 27, ago/set. 2015.

NAMUR, Samir. A tutela das famílias simultâneas. In: FACHIN, Luiz Edson.; TEPEDINO,

Gustavo. Diálogos sobre direito civil. Rio de Janeiro: Renovar, 2008.

PEREIRA, Rodrigo da Cunha. Princípios fundamentais norteadores do direito de família. 2. ed. São Paulo: Editora Saraiva, 2012.

PETRINI, João Carlos. Notas para uma antropologia da família. In: Cristiano Chaves 
de Farias (coord.) Temas Atuais de Direito e Processo de Família: primeira série. Rio de Janeiro: Editora Lumen Juris, 2004.

RAMIDOFF, Mário Luiz. Lições de direito da criança e do adolescente: ato infracional e medidas socioeducativas. Curitiba. Editora Juruá, 2006.

SILVA, Fernando Moreira Freitas. Decreto que Estabelece Procedimentos para Escutas de Crianças e Adolescentes é Promulgado. Entrevista concedida ao IBDFAM: 2018. Fonte: Assessoria de Comunicação do IBDFAM. Publicado em: 12 dez. 2018. Disponível em: http://www.ibdfam.org.br/noticias/6837/+Decreto+que+estabelece+procedimentos + para + escuta + de + crian $\% \mathrm{C} 3 \% \mathrm{~A} 7 \mathrm{as}+\mathrm{e}+$ adolescentes $+\%$ C3\%A9+promulgado. Acesso em: 13 fev. 2019.

TOSTA, Marlina Cunha. Síndrome de alienação parental: a criança, a família e a lei. 2013. 38f. Trabalho de Conclusão de Curso. Graduação em Ciências Jurídicas e Sociais. Pontifícia Universidade Católica do Rio Grande do Sul- PUCRS. Porto Alegre, 2013. Disponível em: http://www3.pucrs.br/pucrs/files/uni/poa/direito/marlina_tosta. pdf. Acesso em: 28 jan. 2019.

VELOSO, Zeno. Nome civil da pessoa natural. In: Rodrigo da Cunha Pereira (coord.). Tratado de direito das famílias. 2. ed. Belo Horizonte: Editora IBDFAM, 2016.

VERONESE, Josiane Rose Petry; SANCHES, Helen Crystine Corrêa. Direito da criança e do adolescente: novo curso, novos temas. Rio de Janeiro: Editora Lumen Juris, 2017.

VILLELA, João Baptista. Desbiologização da paternidade. Revista da Faculdade de Direito da Universidade Federal de Minas Gerais, n. 21, p. 415, maio 1979. Disponível em: https://www.direito.ufmg.br/revista/index.php/revista/article/view/1156/1089. Acesso em: 18 mar. 2019.

Recebido em: 30/04/2019

Aprovado em: 11/06/2019 